DOI: $10.17976 / j p p s / 2018.02 .13$

\title{
КУЛЬТУРНОЕ МНОГООБРАЗИЕ И СУДЬБЫ НАЦИЙ
}

\section{И.П. Цапенко}

ЦАПЕНКО Ирина Павловна, доктор экономических наук, зав. сектором ИМЭМО РАН им. Е.М. Примакова. Для связи с автором: tsapenko@bk.ru

Цапенко И.П. Культурное многообразие и судьбы наций. - Полис. Политические исследования. 2018. № 2. C. 173-183. https://doi.org/10.17976/jpps/2018.02.13

Статья подготовлена при поддержке РГНФ, проект № 16-07-00008 “Интеграция инокультурных мигрантов: перспективы интеркультурализма”.

Статья поступила в редакцию: 13.07.2017. Принята к печати: 30.10 .2017

Аннотация. Рецензируемая коллективная монография “Культурная сложность современных наций” посвящена крайне актуальным вопросам национального и государственного строительства. Данная проблематика рассматривается одновременно в двух ракурсах усложнения мира: внутреннего культурноидентитарного разнообразия жителей современных национальных государств и множественности страновых культурных моделей этих государств на их разных исторических этапах. Усиление плюрализма и многовариантность развития современного мира побудили авторов к разработке новых концептуальных подходов к категоризации этого мира и рассмотрению общественных процессов в новых аналитических координатах. Исследователи расширяют понятие разнообразия, делая его еще более многогранным и акцентируя его стилевой компонент. Мультикультурализм как модель управления культурными различиями в “старых" нациях представлен в разных ипостасях. В книге проводится плодотворная "ревизия" в употреблении категории нации. Демонстрируется преходящий характер, социальнополитическое и региональное своеобразие этого феномена, множественность форм национально-государственных образований. Гибридный, кентавроподобный характер новых коллективностей, возникших в постколониальный период, порожден заимствованием ими политических институтов и правовых норм западных обществ и насаждением этих инородных моделей в несоответствующую им социокультурную среду. Размышляя о судьбах наций в мире, становящемся постнациональным, авторы пишут о возможности формирования постнациональных государств. Вероятно, таким социальным коалициям будет присущ отказ от национального суверенитета как главного атрибута государства в пользу трансгосударственных институтов управления, современными примерами которых могут служить транснациональные союзы, трансграничные конфессиональные сообщества, представляющие своего рода нации-общности, создаваемые на основе веры.

Ключевые слова: гражданская и культурная нация; нациестроительство; национальное государство; общества Запада и Востока; постколониальный мир; культура; культурная сложность; идентичность; организация культурного разнообразия; постнациональное будущее.

Коллективная монография “Культурная сложность современных наций”, подготовленная двадцатью российскими учеными под редакцией ведущих отечественных этнологов В.А. Тишкова и Е.И. Филипповой [Культурная сложность... 2016], сфокусирована на исследовании крайне актуальной проблематики нациестроительства. Оправдывая емкое и многозначное название книги, авторы ставят и пытаются найти ответы на фундаментальные вопросы о природе, вариантах развития и судьбах современных наций, о соотношении понятий нации и культуры, о роли культурного разнообразия в жизни нацио- 
нальных государств и возможных способах его организации. Этому благоприятствует логика работы: введение и первая часть содержат постановку главных проблем исследования, вторая часть посвящена давно сформировавшимся, “старым” нациям, третья - недавно сложившимся или еще только складывающимся на постколониальном и постсоциалистическом пространстве нациям, четвертая - специфике восточных вариантов нациестроительства, в заключении намечаются перспективы постнационального развития мира.

Теоретическому дискурсу о проблемах “нациеформирования” [там же: 191] предпослана концептуализация феномена внутреннего усложнения наций, нормативного для эпохи постмодерна. Суть этого процесса в умножении разнообразия идентичностей, происходящего одновременно в нескольких ипостасях. Нарастание этнокультурной мозаичности современного мира, насчитывающего более 5 тыс. этносов, отражает изменения в понятии этноса, связанные со смещением этого понятия в сторону “этничности без групп”, постепенным освобождением последней от внешних предписаний и принудительного группизма. Многокрасочность палитры идентичностей усиливается иммиграцией, под влиянием которой увеличивается пестрота жителей принимающих территорий по странам и регионам происхождения, лингвистическим, конфессиональным, культурно-хозяйственным принадлежностям и отличиям. Этот процесс идет не только извне, но и изнутри обществ-реципиентов, в которых размываются межгрупповые границы, и на перекрестках разных культур, в зоне их интерференции, происходит диффузия исходных культурных идентичностей [Эпштейн 2007: 90], выстраиваются новые - транскультурные - типы самокатегоризации, которые в процессе последующего кросс-культурного взаимообогащения претерпевают дальнейшие метаморфозы. Данные линии умножения разнообразия наряду с этнореификацией, ростом партикулярных форм самосознания, формированием новых субкультур, или квир-народов (интернет-сообществ, стритрейсеров и пр.) [Культурная сложность... 2016: 4-6, 14] намечены в книге. С усилением плюрализма и многовариантности развития категоризация современного мира уже не вмещается в традиционные схемы, в существующее "расписание жителей Земли по этносам как изначальным архетипам" [там же: 13], требуя расширения понятия разнообразия и придания ему новых граней.

Такой более объемный конструкт разнообразия представлен В.С. Малаховым, который выделяет этническое, конфессиональное, идеологическое, пространственно-географическое и жизненно-стилевое измерения культурной неоднородности современной России [там же: 197]. При этом становится все более значимым стилевой срез гетерогенности современных социумов, что подмечает на материале Германии Ю.В. Бучатская, хотя, возможно, и преувеличивая роль этого компонента: "Культурная сложность сегодняшнего общества проявляется не в культурных различиях между этносами или религиями, а в многообразии стилей жизни... люди, принадлежащие к одному стилю жизни, но этнически разные (немец и марокканец) будут друг другу ближе и понятнее, чем другой такой же немец, сосед, рожденный в Германии, но исповедующий другой стиль жизни, а значит, говорящий буквально на другом символическом языке" [там же: 132].

Происходящие в развитых регионах мира многоплановые культурные сдвиги, квалифицируемые немецким культурологом С. Вертовеком как “трансфор- 
мирующая диверсификация разнообразия" (transformative diversification of diversity), как “сверхразнообразие” (super-diversity) [Vertovec 2007: 1025], становятся все более значимым фактором функционирования современных наций. Такие социумы наделяются “преимуществами разнообразия”, способного выступать в роли ресурса развития, “источника здоровья, богатства и могущества нации" [Zachary 2003]. Как пишет Д.М. Бондаренко, “равноправное сосуществование множества культурных идентичностей акцентируется ныне как новая базовая национальная ценность, как источник национального развития в современных условиях интенсивной глобализации” [Культурная сложность... 2016: 240]. Немалый позитивный заряд несут “экономика разнообразия” и “социальный капитал разнообразия" [The Economics... 2015; Rouble 2005].

В то же время очевидно, что культурные различия нередко ведут к фрагментации и становятся детонатором этнополитической конфликтности в современных нациях. Более того, нарастающая культурная разнородность и формирование “параллельных обществ” привели к кризису самосознания населения, представляющего как “культурное ядро” современных наций, так и их новых жителей. А эти процессы, как отмечает В.А. Тишков, “завели в тупик сам вопрос 'что есть нация?'” [Культурная сложность... 2016: 5].

В книге нет однозначного ответа на этот вопрос. И его отсутствие вытекает из многоликости и многомерности данного конструкта. Отталкиваясь от принятых дефиниций двух типов наций, или форм категоризации населения: конструктивистского понятия гражданско-политической нации, объединяющей сограждан, и примордиалистской трактовки этнонации, состоящей из этнофоров, В.А. Тишков, предлагает двойственное определение нации - как обозначающей и гражданско-политический, и этнокультурный типы социальных коалиций. Однако применительно к “новым” нациям, где государственная политика направлена на легитимизацию политического режима на основе укрепления политической нации, возможно, уместно поставить вопрос о разведении понятий политической (государствообразующей, опирающейся на правовой институт гражданства) и гражданской (соединенной скрепами социальных взаимодействий) наций. Именно на такой позиции стоит коллектив авторов из ИМЭМО [Семененко, Лапкин, Пантин, Бардин 2017].

Опираясь на идею Б. Андерсена о воображаемых сообществах, авторы книги проводят плодотворную "ревизию” в употреблении категории нации, придавая ему множественный смысл. Так, согласно В.А. Тишкову, “нация - это форма коллективного сознания (идентичности) людей по поводу принадлежности к определенной общности, которую они считают нацией” [Культурная сложность... 2016: 9]. В.С. Малахов, подметивший, что культурные и политические границы редко совпадают [Малахов 2014], вводит авторское понятие нации как "пространства коммуникации (политической, экономической, культурной)" [Культурная сложность... 2016: 190] и, исходя из этого понятия, утверждает, что нация в современной России существует. С.В. Соколовский, критикуя выделение гражданских наций и этнонаций, справедливо считает, что существует не два типа нации, а два конкурирующих описания единого процесса нациогенеза, застигнутого на его разных стадиях и с различающейся концептуализацией различий [там же: 51]. Эта идея укладывается в существующее представление о том, что “нация-государство есть исторически и пространственно ограниченный феномен, связанный с опре- 
деленной стадией развития общества” [там же: 19], не будучи универсальной, безальтернативной моделью государственности.

Весьма интересно суждение Е.И. Филипповой о том, что национальная идентичность, подразумевающая чувство солидарности и коллективного членства, трансформируется с течением времени в этничность (т.е. субъективное ощущение культурного единства). Более того, в результате смещения баланса между гражданской и культурной идентичностью в пользу последней в условиях глобальной миграции и этнизации национальной (гражданской) принадлежности происходит по сути “расиализация 'гражданских наций”" [там же: 28].

На пересечении проблемных полей многообразия населения страны и нациестроительства возникает один из ключевых вопросов современного общественного развития, решение которого приобретает экзистенциальный характер: как адекватно организовать это разнообразие и одновременно обеспечить гражданское единство и согласие в многорелигиозной, многорасовой и многоэтничной нации. Эта насущная проблема для многокультурных обществ, с которой они будут сталкиваться в ближайшие десятилетия, заострена в одном из прогнозов ИМЭМО [Мир 2035... 2016: 74].

В книге утверждается, что “формула ‘единство в многообразии” как основа политического устройства и управления находится в арсенале большинства современных государств”, и что “признанное многообразие и есть единство” [Культурная сложность... 2016: 18]. Однако учитывая сильный ассимиляторский крен современной политики в отношении мигрантов и этнических менышинств в развитых регионах мира, правомерность подобной позиции вызывает сомнение. Не вполне подтверждает это и опыт мультикультурализма, заострившего проблемы и культурного и гражданского единства. Как пишет Е.И. Филиппова: “Мультикультуралистский дискурс зачастую призван замаскировать дискриминацию и исключение другого... Под лозунгом права на различие культура воздвигает жесткие границы внутри современных обществ...” [там же: 27].

Соглашаясь с критикой мультикультурализма, в то же время можно предположить, что этот курс, как и феномен нации, - исторически преходящий феномен. Более того, для успешности этого курса необходимы определенные общественные условия. Недавние террористические акты, совершенные в европейских странах их новыми гражданами из числа мигрантов с исламского Востока, равно как и насильственные действия коренных белых жителей в отношении мусульман, уже не оставляют никаких сомнений в провале мультикультурализма на континенте. Но, тем не менее, Л.К. Мамедова показывает, что в предыдущие десятилетия такая политика продемонстрировала в Великобритании немало достоинств. Среди них - образовательные успехи небелых жителей (так наз. $B A M E$ ), рост в их массе средних слоев, их активное участие в политической жизни, лояльность мусульман британской нации, поддержка ее внешнеполитического курса, размывание границ этнических анклавов и т.д. Трудно не согласиться, что “мультикультурализм жизнеспособен при сильной поддержке чувства общности у граждан принимающей страны” [там же: 87], однако разворачивающийся кризис национальной идентичности лишает этот курс необходимой опоры.

Весьма привлекателен и австралийский опыт проведения официальной политики мультикультурализма, направленной на формирование общенациональной идентичности и социальную сплоченность общества в условиях 
культурного многообразия. Как пишет И.Г. Остроух, “несмотря на разность происхождения и культур, в своем многообразии австралийцы - это единая нация" [там же: 185]. Если интеграция аборигенов сталкивается с немалыми социально-экономическими проблемами, то встраивание приезжих в австралийский социум проходит относительно успешно. Последнее, как показывает автор, достигается в первую очередь благодаря активной политике мультикультурализма, в рамках которой все вновь прибывшие получают доступ к бесплатному медицинскому обслуживанию, образовательным и семейным программам, а через два года - право на получение нового гражданства без отказа от предыдущего и т.д. Почему же модель, потерпевшая провал в Европе, проявила жизнеспособность на “зеленом материке”? Вероятно, источники последней следует искать в специфике австралийской культуры, в которой мужское братство и товарищество (mateship) олицетворяют солидарность и взаимопомощь и являются отличительными чертами национального характера, формируют столь необходимую для интеграции приезжих и столь недостающую основной массе европейских поселений толерантную среду. Важен также и состав инокультурных мигрантов. В отличие от мусульман, не только трудно ассимилируемых европейскими социумами, но и несущими им угрозы исламизации и обострения культурных антагонизмов, в Австралии среди уроженцев развивающихся стран доминируют выходцы из Китая и Индии, обладающие, как известно, немалым интеграционным потенциалом.

И тем не менее в европейских городах есть успешные интеграционные практики. Ю.В. Бучатская приводит интересные факты о сосуществовании и гибридизации немецкой и мигрантских культур в Берлине. Эти факты свидетельствуют, что, согласно модели Г. Зиммеля, "в толерантной среде городское пространство становится лабораторией социальных экспериментов, местом, где происходят контакты и реализуются общественно-политические проекты локального коллектива", которое объединяет сограждан следованием общим ценностям, заинтересованностью в общем благе, общей локальной идентичностью. Как продемонстрировано в данной главе, “городу удалось стать 'идентичность-образующей’ общностью для всех его граждан, несмотря на растущее экономическое неравенство и социальную гетерогенность” [там же: 130]. Добиться позитивного совмещения культурных идентичностей местных и приезжих жителей с городской гражданской идентичностью, преодолеть или смягчить на микроуровне антагонизмы “мы - чужие" и обеспечить гражданское согласие удалось в результате такого “культурного полилога... где культуры встречаются, взаимодействуют, но не сливаются, сохраняя свое право на 'непрозрачность”" [Тлостанова 2008: 153]. Это, по сути, пример успешного опыта реализации европейского проекта интеркультурных городов, о котором, как и интеркультурализме в целом, обещающем прийти на смену ассимиляционному подходу и мультикультурализму на континенте [Цапенко 2017], к сожалению, не упоминается в книге.

Представляют интерес и другие приводимые в книге страновые примеры организации культурного разнообразия в “старых” нациях. Глава Т.Б. Коваль посвящена проблемам построения “государства автономий” в постфранкистской Испании. В Испании сложился “лабиринт идентичностей”: хотя для большинства жителей основа общности - кастильский язык и единство истории, они ощущают сильную связь прежде всего с местом рождения и жительства, затем с регионом и только потом с Испанией. Подобная иерархия 
идентичностей формирует питательную среду для сепаратизма, представляющего серьезную угрозу для единства страны.

Д.Н. Караваева отмечает происходящее в условиях глобализации и евроинтеграции существенное усиление английскости как совокупности английских культурно-исторических ценностей и ориентаций, по сравнению с британскостью, выступающей в качестве концепта зонтичной гражданской идентичности (имперской и постимперской) [Культурная сложность... 2016: 99]. Под влиянием миграционного кризиса, спровоцировавшего Brexit, происходит ренессанс модели классической Англии и акцентируется отрицание разнообразия [там же: 101], что чревато реактивным усилением инокультурных идентичностей и углублением существующих межгрупповых разломов.

Н.В. и И.М. Моховы показывают кризис французской республиканской модели политической ассимиляции мигрантских общин, проявляющийся в частности в росте этнических анклавов и распространении исламизма. Происходящая в условиях глобализации и инокультурной иммиграции эрозия национальной идентичности способствует подъему национализма. Антииммиграционная политика “Национального фронта” ведет к дальнейшему углублению социальных разломов во французском социуме.

Весьма проблематичен и статус французского населения заморских территорий и департаментов. Множественность самоопределений “французов с островов” рассмотрена на примере Гваделупы Е.И. и В.Р. Филипповыми. Доминируют три уровня коллективной идентификации: гваделупская - культурная, антильская - применительно к небелым, французская - политическая [там же: 172-174]. Глава содержит четкую трактовку вызывающего немало разночтений термина “креол” как обозначающего носителя особого образа жизни и системы поведения, формирующейся в результате биологической “метисации”, но прежде всего культурного синтеза локального и пришлого элементов в американском географическом пространстве [там же: 160].

Отмечая оригинальность и фундированность представленного материала по “старым” нациям, остается лишь выразить сожаление, что в работе не нашел отражения интересный и поучительный опыт нациестроительства в таких крупных и относительно крупных странах, как США, Канада и Италия.

Большое разнообразие форм демонстрируют и новые национальногосударственные образования, складывающиеся на обломках старого мира. В.С. Малахов излагает авторскую трактовку опыта нациестроительства и организации культурного многообразия в Российской империи, СССР и современной России. Автор подчеркивает, что становление гражданской нации в царской России было проблематично в силу ее имперского характера и малочисленности граждан среди подданных, основную массу которых составляло бесправное крестьянство [там же: 192]. Он отмечает и вынужденный характер культурного разнообразия в СССР, обусловленный этнодемографическими и политико-идеологическими причинами. Исследователь называет такое разнообразие в постсоветской России оспариваемым: с официальной риторикой многокультурности соседствует явное нежелание смириться с последней. От новоприбывших ожидают или полной культурной конформности - растворения в социокультурном мейнстриме - или выезда из страны [там же: 204].

Глава М.Ю. Мартыновой повествует о тернистом, полном коллизий идентичностей пути становления нации в Боснии и Герцеговине. Целый ряд 
признаков, приводимых автором, свидетельствует о существовании в стране так наз. этнической демократии: связь права занятия должностей в органах управления с этнической принадлежностью гражданина к трем “конституционным" народам - бошнякам, хорватам и сербам; законодательное лишение доступа к высшим управленческим должностям представителей 17 проживающих в стране меньшинств и др. Нельзя не согласиться и с тем, что гипертрофированная роль этнического фактора в общественной жизни затрудняет формирование гражданского единства.

В начале книги С.В. Соколовский предостерегает против "концептуального империализма", равно как и отказа от рассмотрения несовременных обществ как отклоняющихся от западного канона случаев, считая необходимым изменить принципы категоризации мира [там же: 54]. Исследуя с этой позиции проблемы формирования наций в постколониальном мире на материале Танзании и Замбии, Д.М. Бондаренко приходит к важному концептуальному выводу: “начав складываться в своем нынешнем виде в колониальный период, а потому воспроизводя форму политических институтов и правовые нормы Запада Нового времени, постколониальное государство не могло автоматически усвоить присущее им содержание, вложенное гражданским обществом, самостоятельно сложившимся в Европе, но не в Азии и Африке. Наиважнейшей особенностью процесса формирования наций в постколониальных странах является изначально ведущая роль в нем не общества, а государства” [там же: 225], которое к тому же зачастую оказывается недостаточно эффективным.

Высказанные Д.М. Бондаренко идеи находят подтверждение в главе Н.В. Мохова, посвященной нациестроительству в Алжире, где для модернизации общества и решения насущных проблем также заимствовались тогдашние восточноевропейские, или социалистические модели. При этом “правящая элита стремилась построить алжирскую нацию словно крепкий 'монолит с единым арабо-мусульманским обликом', который, однако, не в полной мере отражал существовавшее в алжирском обществе разнообразие культур и идентичностей” [там же: 257]. Нельзя не согласиться с автором, что конфликтный симбиоз социально-культурных и религиозных объединений ставит под вопрос не только возможность объединения "расколотой” нации, но и саму идею нации.

В главе В.Р. Филиппова и Э.Т. Дикко показаны трудности формирования малийской нации, которые определяются сложной композицией языков, культур, религий, традиций, хозяйственных укладов, или “культур жизнеобеспечения" (миролюбивых земледельцев, охотников и рыбаков, сосуществующих с вольными и воинственными кочевниками - скотоводами, торговцами, “корсарами пустыни”) [там же: 275]. Это многообразие преломляется в расколе общества на южан и северян. В то же время, как справедливо считают авторы, общая травма угнетения, религиозное единение на почве “спокойного” ислама суннитского толка и др. могут стать залогом успешности проекта плюралистичного будущего малийской нации.

Глава И.И. Филатовой повествует о попытке построения пострасового общества - так наз. радужной нации в ЮАР после отмены апартеида. Однако программа Африканского национального конгресса уже изначально была направлена на сборку “африканской нации, базирующейся на единении различных африканских идентичностей. Не-африканцы могли стать членами этой нации, только если они отвергали свою собственную идентичность и прини- 
мали африканскую” [там же: 298]. Напрашивающиеся на аналогии с советскими “законы о позитивных действиях привели к поистине фантастическим попыткам расовой инженерии” [там же: 300]. Политика “расовой репрезентативности" вызвала возрождение апартеида - в новой форме черного расизма. Приведенные факты свидетельствуют, что расовые квоты и преференции при приеме на работу, выборе деловых партнеров и т.п. противоречили принципам эффективности. Как справедливо отмечает И.И. Филатова, “редистрибутивные” меры вызвали отток из страны квалифицированных представителей белой и индийской общин и их капитала, а многие социальноэкономические проблемы так и остались нерешенными.

Авторскому коллективу удалось показать яркую специфику культурной сложности наций и их сборки на Востоке. Однако специальная глава по Индии, несомненно, украсила бы работу.

Глава А.А. Закурдаева посвящена китайской национальной идентичности, представление о которой основывается на положении древнекитайской философии о том, что любой объект как единое целое функционирует вследствие противостояния противоположностей (инь и ян) [там же: 307]. Как показано в книге, идентификация с нацией выстраивается на основании развития отношений между доминирующим народом (ян) и остальными народами, выступающими в роли инь. Или же между китайцем-управленцем доминантной стороной - и обычным китайцем, принимающим его политику [там же: 312]. Отмечая, что консолидация китайского общества опирается на комплекс факторов, А.А. Закурдаев, как представляется, верно выделяет особо важную роль “китайской мечты”, содержание которой связывается c “Великим возрождением китайской нации” [там же: 322].

В главе Е.Л. Скорцовой приводится оригинальное сопоставление характерных черт западной и японской культур. Без учета этих различий представителям западных обществ, пытающимся некритически перенести на эти общества западные модели и аналитические категории и втиснуть “текучесть, процессуальность, бесформенность”, музыкальность и темпоральность культуры Востока [там же: 332] в прокрустово ложе рационалистических конструкций, не понять японцев. Автор подчеркивает, что в японском языке отсутствует слово “личность”, и высшей добродетелью человека традиционно признавалась ответственность по отношению к коллективу, четко соблюдавшаяся в самурайской среде и являвшаяся характерной особенностью японской культуры. Этим исследователь объясняет и специфику идентификации японцев, выстаивающейся в результате постоянных отношений между представителями данной культуры. Формирующееся в ходе этих отношений “поле взаимного доверия" айдагара - и составляет основу существования и развития как социума в целом, так и отдельного человека [там же: 339]. Формирование такой культуры доверия приобретает все большую значимость и для западных обществ в контексте развития правового государства [Мир 2035... 2016: 81].

Глава А.Н. Мещерякова, повествующая о периоде императора Мэйдзи, интересна аналогиями с советской историей. “Достижения Японии в экономике, образовании и военном деле были бы невозможны, если бы японцы не воодушевлялись идеями создания страны-нации, идеями, которые прочно овладели самыми широкими массами. Японцы гордились своей землей, и эта гордость давала им уверенность в осуществимости самых грандиозных планов по преобразованию страны и мира" [Культурная сложность... 2016: 358]. 
Как особый тип социального образования описывает Г.Г. Косач Саудовскую Аравию, где, согласно Основному закону правления, власть принадлежит сыновьям короля Аль Сауда и их сыновьям, клятвой верности им “связывая народ с правящей семьей, давшей народу название, а не с территорией, населенной человеческим сообществом" [там же: 362]. В саудовском дискурсе такая коллективность, базирующаяся на лояльности династии и единстве вероисповедания, называется не нацией, а уммой, обозначающей сообщество приверженцев ислама. Как пишет автор, ваххабизм в силу его чрезмерного ригоризма не способен стать культурной основой национальной идентичности, а проводимая властью политика, игнорирующая многообразие общества, порождает партикулярные идентичности, а не чувство принадлежности к государству [там же: 374]. Народ же, населяющий страну, понимается как территориальная организация - шааб. Именно такое определение общности создает базис для категоризации саудовцев в качестве национального целого [там же: 363]. Вероятно, как полагает автор, “саудовская идентичность” станет реальностью только при условии выхода на арену политической жизни современного общественного слоя [там же: 375].

На протяжении книги ее авторы неоднократно обращаются к вопросу о судьбах наций в мире, становящемся “постнациональным”. Как пишет Д.М. Бондаренко, “глобализация ставит под сомнение будущее и национального государства как формы политической организации, и концепции суверенитета как фундамента его легитимности. Вероятно... нас ждет появление на свет и постнационального государства, одним из оснований которого будет отказ от национального суверенитета (но не политической независимости) как главного атрибута государства в пользу трансгосударственных институтов управления” [там же: 240]. Примерами таких институтов могут служить транснациональные союзы, трансграничные конфессиональные сообщества (умма), представляющие своего рода нации-общности на основе веры.

С учетом постнациональной перспективы мира, в котором, говоря словами А. Дьеккоффа, нации могут начать жить отдельной от государств жизнью, В.А. Тишков и Е.И. Филиппова предлагают отказаться от "методологического национализма”, рассматривающего государства и культуры как онтологические целостности [там же: 378]. Признавая ограниченность самой метакатегории “нация", ее преходящий характер, историческое, социально-политическое и региональное своеобразие, В.А. Тишков и Е.И. Филиппова акцентируют в то же время сохраняющуюся почти глобальную значимость самой процедуры нациестроительства [там же: 382]. Нельзя не согласиться с их мнением, что переживаемый национальными государствами в менее развитой части мира кризис - это кризис не постсовременности, а недостаточной современности [там же: 381].

Таким образом, рецензируемая книга представляет собой значительный прорыв в освоении проблемных полей культурной сложности и нациестроительства. В этом глубоком фундаментальном междисциплинарном исследовании предлагаются совершенно новые концептуальные подходы к пониманию широкого пласта исследуемых вопросов, разрабатываются новые принципы категоризации современного усложнившегося мира, применяются новые аналитические модели развивающихся общественных процессов. Исследование отличается масштабностью и многоплоскостным характером, представляя одновременно глобальное и локальное, “старые” и “новые” нации, культуры Запада и Востока, исторические истоки, современное состояние и вероятное 
будущее наций. Создаваемые теоретические конструкции опираются на многочисленные фактические примеры и статистические данные.

Эта монография, увлекающая читателей в путешествие по лабиринтам размышлений о происходящих изменениях в мироустройстве и представлениях о нем, будет представлять интерес для всех, кто стремится постичь реалии современного мира, а также предвидеть его возможное постнациональное будущее. Дав старт осмыслению общественных процессов в новом концептуальном ключе, книга побуждает к последующим исследованиям в этой области.

Культурная сложность современных наций. 2016. Отв. ред. В.А. Тишков, Е.И. Филиппова; Институт этнологии и антропологии им. Н.Н. Миклухо-Маклая РАН. М.: Политическая энциклопедия. 384 с.

Малахов В.С. 2014. Культурные различия и политические границы в эпоху глобальных миграций. М.: Новое литературное обозрение. 232 с.

Мир 2035. Глобальный прогноз. 2016. Под ред. А.А. Дынкина; ИМЭМО им. Е.М. Примакова РАН. М.: Магистр. 352 с.

Семененко И.С., Лапкин В.В., Пантин В.И., Бардин А.Л. 2017. Между государством и нацией: дилеммы политики идентичности на постсоветском пространстве. - Полис. Политические исследования. № 5. С. 54-78. https://doi.org/10.17976/jpps/2017.05.05

Тлостанова М.В. 2008. От философии мультикультурализма к философии транскультурации. М.: РУДН. 251 с.

Цапенко И.П. 2017. Интеркультурная парадигма интеграции мигрантов. - Вестник Российской академии наук. № 10. C. 915-926. https://doi.org/10.7868/S0869587317100061

Эпштейн М.Н. 2007. Транскультура и трансценденция. - Только уникальное глобально: Личность и Управление. Культура и Образование. СПб.: СПбГУКИ. С. 90-102.

Rouble B. 2005. Creating Diversity Capital: Transnational Migrants in Montreal, Washington and Kyiv. Washington: Woodrow Wilson Center Press. 267 p.

The Economics of Cultural Diversity. 2015. Ed. by P. Nijkamp, J. Poot, J. Bakens. Cheltenham: Elgar Publishing. 465 p.

Vertovec S. 2007. Super-Diversity and Its Implications. - Ethnic and Racial Studies. Vol. 30. No. 6. P. 1024-1054. https://doi.org/10.1080/01419870701599465

Zachary G. 2003. The Diversity Advantage: Multicultural Identity in the New World Economy. Boulder, CO: Westview Press. 352 p.

DOI: $10.17976 /$ jpps/2018.02.13

\section{CULTURAL DIVERSITY AND THE DESTINY OF NATIONS}

\section{I.P. Tsapenko ${ }^{1}$}

${ }^{1}$ Primakov National Research Institute of World Economy and International Relations (IMEMO), Russian Academy of Sciences. Moscow, Russia

TSAPENKO Irina Pavlovna, Dr. Sci. (Econ.), Head of Section, Primakov National Research Institute of World Economy and International Relations (IMEMO), Russian Academy of Sciences. Email: tsapenko@bk.ru

Tsapenko I.P. Cultural Diversity and the Destiny of Nations. - Polis. Political Studies. 2018. No. 2. P. 173-183. (In Russ.) https://doi.org/10.17976/jpps/2018.02.13

Acknowledgements. This book review was prepared with financial support provided by the Russian Foundation for Humanities (research grant № 16-07-00008 “Integration of Migrants with Different Cultural Background: Prospects of Interculturalism"). 
Abstract. The reviewed collective study "Cultural Complexity of Modern Nations" is devoted to the actual issues of nation and state building. These problems are considered within two frameworks of the world complexity: internal cultural identity diversity of the inhabitants of modern nation-states and plurality of country cultural patterns of these states at their different historical stages. Pluralism and multivariance of the modern world development have prompted the authors of this work to develop new conceptual approaches to the categorization of this world and to consider social processes within new analytical reference systems. Researchers are expanding the notion of diversity, making it even more versatile and accentuating its style difference component. Multiculturalism as a model of management of cultural differences in the "old" nations is presented in different guises - not only as a collapsed European integration project. This approach shows viability on the Australian continent. And according to Berlin example, many successes are on account of the successor of such policies, interculturalism, at the local level. The authors realize a fruitful "revision" of the used category of the nation, to which a plural meaning is attached. They demonstrate a transient nature, socio-political and regional specificity of this phenomenon, multiplicity of forms of nation and state formations. Hybrid, centaur-like type of new collectivities that emerged in the postcolonial period, is generated by their borrowing political institutions and norms of Western societies and the imposition of foreign models into inappropriate social and cultural environment. Pondering over the destiny of nations in the world, which is becoming postnational, the authors raise the possibility of the formation of post-national states. Probably one of the characteristics such social coalitions will be the abandonment of national sovereignty as the main attribute of the state in favor of trans-state institutions of governance. Their modern examples are transnational unions, cross-border religious communities as a kind of nation-community, created on the basis of faith.

Keywords: civil and cultural nation; nation-building; nation-state; Western and Eastern societies; postcolonial world; culture; cultural complexity; identity; management of cultural diversity; postnational future.

\section{References}

Epshtein M.N. Transkul'tura i transtsendentsiy [Transculture and Transcendence]. - Tol'ko unikal'noe global'no: Lichnost' $i$ Upravlenie. Kul'tura i Obrazovanie [Only the Unique One Is Global: Personality and Management. Culture and Education]. Saint Petersburg: SPbGUKI. 2007. P. 90-102. (In Russ.)

Kul'turnaya slozhnost' sovremennykh natsii. Otv. red. V.A. Tishkov, E.I.Filippova; Institut etnologii i antropologii im. N.N. Miklukho-Maklaya RAN [The Cultural Complexity of Modern Nations. Ed. by V.A. Tishkov, E.I.Filippova, N.N. Miklouho-Maklay Institute of Ethnology and Anthropology, RAS]. Moscow: Politicheskaya entsiklopediya. 2016. 384 p. (In Russ.)

Malakhov V.C. Kul'turnye razlichiya i politicheskie granitsy v epokhu global'nykh migratsii [Cultural Difference and Political Borders in the Age of Global Migrations]. Moscow: Novoe literaturnoe obozrenie. 2014. 232 p. (in Russ.)

Mir 2035. Global'nyi prognoz. Pod red. A.A. Dynkina; IMEMO im. E.M. Primakova RAN [World 2035. Global Forecast]. Moscow: Magistr. 2016. 352 p. (In Russ.)

Rouble B. Creating Diversity Capital: Transnational Migrants in Montreal, Washington and Kyiv. Washington: Woodrow Wilson Center Press. 2005. 267 p.

Semenenko I.S., Lapkin V.V., Bardin A.L., Pantin V.I. Between the State and the Nation: Dilemmas of Identity Policy in Post-Soviet Societies. - Polis. Political Studies. 2017. No. 5. P. 54-78. (In Russ.) https:// doi.org/10.17976/jpps/2017.05.05

The Economics of Cultural Diversity. Ed. by P. Nijkamp, J. Poot, J. Bakens. Cheltenham: Elgar Publishing. 2015. $465 \mathrm{p}$.

Tlostanova M.V. Ot filosofii mul'tikul'turalizma k filosofii transkul'turatsii [From Philosophy of Multiculturalism Towards Philosophy of Transculturation]. Moscow: RUDN. 2008. 251 p. (In Russ.)

Tsapenko I.P. An Intercultural Program of Migrant Integration. - Herald of the Russian Academy of Sciences. 2017. No. 5. P. 454-463. (In Russ.) https://doi.org/10.1134/S1019331617050094

Vertovec S. Super-Diversity and Its Implications. - Ethnic and Racial Studies. 2007. Vol. 30. No. 6. P. 1024-1054. https://doi.org/10.1080/01419870701599465

Zachary G. The Diversity Advantage: Multicultural Identity in the New World Economy. Boulder, CO: Westview Press. 2003. 352 p. 